\title{
Investigation on the Effect of Atmosphere on the Pyrolysis Behavior and Oil Quality of Jimusar Oil Shale
}

\author{
Zhiqin Kang $\mathbb{D}^{1,2}$ Zhijing Wang, ${ }^{1,2}$ Yang Lu $\mathbb{D}^{1,2}$ Ran Cao, ${ }^{1,2}$ Dongwei Huang, ${ }^{1,2}$ \\ and Qiaorong Meng ${ }^{3}$ \\ ${ }^{1}$ Key Laboratory of In-Situ Property-Improving Mining of Ministry of Education, Taiyuan University of Technology, \\ Taiyuan 030024, China \\ ${ }^{2}$ The In-Situ Steam Injection Branch of State Center for Research and Development of Oil Shale Exploitation, Taiyuan University \\ of Technology, Taiyuan 030024, China \\ ${ }^{3}$ College of Mining Engineering, Taiyuan University of Technology, Taiyuan 030024, China
}

Correspondence should be addressed to Yang Lu; luyang0116@link.tyut.edu.cn

Received 22 January 2022; Accepted 17 February 2022; Published 2 March 2022

Academic Editor: Yu Zhao

Copyright (C) 2022 Zhiqin Kang et al. This is an open access article distributed under the Creative Commons Attribution License, which permits unrestricted use, distribution, and reproduction in any medium, provided the original work is properly cited.

High-temperature $\mathrm{H}_{2} \mathrm{O}$ and $\mathrm{CO}_{2}$ can improve the pyrolysis behavior of oil shale. Therefore, in this paper, Jimusar oil shale was selected as the research object and the effect of the reaction atmosphere $\left(\mathrm{H}_{2} \mathrm{O}, \mathrm{CO}_{2}\right.$, and $\left.\mathrm{N}_{2}\right)$ on its pyrolysis behavior, pyrolysate distribution, and pyrolysis oil quality was fully compared and studied. The results showed that compared with the $\mathrm{N}_{2}$ atmosphere, the presence of $\mathrm{H}_{2} \mathrm{O}$ and $\mathrm{CO}_{2}$ both increased the weight loss and weight loss rate during pyrolysis of oil shale and the existence of $\mathrm{H}_{2} \mathrm{O}$ advanced the initial precipitation temperature of volatiles by $17^{\circ} \mathrm{C}$. The comprehensive release characteristic indices of volatiles during pyrolysis of oil shale in the $\mathrm{CO}_{2}$ and $\mathrm{H}_{2} \mathrm{O}$ atmospheres increased by $49.34 \%$ and $114.35 \%$, respectively, which significantly improved its pyrolysis reactivity. Both $\mathrm{H}_{2} \mathrm{O}$ and $\mathrm{CO}_{2}$ atmospheres improved the pyrolysis oil yield of oil shale, and the pyrolysis oil yield in the $\mathrm{H}_{2} \mathrm{O}$ atmosphere performed better than that in the $\mathrm{CO}_{2}$ atmosphere. Especially, the $\mathrm{H}_{2} \mathrm{O}$ atmosphere could increase the pyrolysis oil yield by $41.42 \%$. The existence of $\mathrm{CO}_{2}$ prevented methyl radicals from accepting hydrogen radicals during pyrolysis and reduced the alkane yield, while $\mathrm{CO}_{2}$ participated in the addition reaction of alkane, which increased the alkene yield. High-temperature $\mathrm{H}_{2} \mathrm{O}$ provided more hydrogen source, which increased the alkane yield and inhibited the alkene formation. Both $\mathrm{H}_{2} \mathrm{O}$ and $\mathrm{CO}_{2}$ atmospheres promoted the cracking of polycyclic aromatics and increased the yield of small-molecular aromatics in the pyrolysis oil. During the pyrolysis process of oil shale, $\mathrm{CO}_{2}$ and $\mathrm{H}_{2} \mathrm{O}$ underwent reforming reaction with the heavy oil, which increased the light component fraction, thereby increasing the $\mathrm{H} / \mathrm{C}$ ratio of pyrolysis oil. Thus, the existence of $\mathrm{H}_{2} \mathrm{O}$ and $\mathrm{CO}_{2}$ atmospheres improved the quality of pyrolysis oil and the effect of $\mathrm{H}_{2} \mathrm{O}$ was better than $\mathrm{CO}_{2}$. The $\mathrm{H}_{2} \mathrm{O}$ and $\mathrm{CO}_{2}$ atmosphere promoted the formation of a well-developed pore structure, which was conducive to mass and heat transfer during pyrolysis of oil shale.

\section{Introduction}

With the gradual consumption of traditional energy, exploring a clean and efficient alternative nontraditional energy has become a hot topic $[1,2]$. China is rich in oil shale resources, ranking the second in the world, and its proven reserves are 47.6 billion tons (calculated as pyrolysis oil) [3, 4]. Oil shale is a black or brown flaky structure with a dense texture, which is rich in organic kerogen. The shale oil produced from the pyrolysis of oil shale is similar to natural petroleum; thus, oil shale is a high-quality source rock [5]. And, oil shale has become an important strategic reserve resource and supplementary energy in China [6]. The organic matter in oil shale includes kerogen and a small amount of asphaltene. Kerogen is a kind of macromolecule polymer with a three-dimensional network structure. It is mainly composed of aliphatic hydrocarbons and also contains a small amount of aromatic hydrocarbons and oxygen-containing groups, which is the main source of pyrolysis oil and gas products [7-9]. Oil shale has the 
characteristics of high ash content and low thermal conductivity, which lead to some issues such as low oil yield and serious accumulation of waste residues [10, 11]. Therefore, how to improve the yield and quality of pyrolysis oil and its pyrolysis mechanism need to be studied urgently.

Rajeshwar and DuBow proposed that the pyrolysis mechanism of oil shale was a two-step decomposition model, that was, kerogen in oil shale was first converted into asphaltene intermediates at low temperature and, as the pyrolysis temperature increased, asphaltenes were further decomposed into oil, gas, and solid residue. In the first step, when the pyrolysis temperature was $180-350^{\circ} \mathrm{C}$, the polar bridge bonds on the border of the organic kerogen cracked, such as the unstable $-\mathrm{COOH}, \mathrm{C}-\mathrm{O}-\mathrm{C}, \mathrm{C}=\mathrm{O},-\mathrm{CH}_{3}$, and other active groups were thermally broken; thus, some free radicals were generated. The free radicals were combined with each other to form small-molecular compounds and released, and its activation energy was about $15 \pm 2 \mathrm{kcal} / \mathrm{mol}$. When the pyrolysis temperature reached $300-350^{\circ} \mathrm{C}$, the kerogen was converted into asphaltene intermediates. In the second step, when the pyrolysis temperature was $350-500^{\circ} \mathrm{C}$, the cycloalkane or aromatic structure in the core of organic kerogen began to crack. The pyrolysis fragments released and combined to form shale oil and semicoke, and its activation energy is $35 \pm 3 \mathrm{kcal} / \mathrm{mol}$. At the same time, it was accompanied by secondary reactions and additional reactions of volatiles, such as cracking reaction, polymerization reaction, and water gas shift reaction [12]. Li et al. believed that during the pyrolysis of oil shale, the aliphatic groups outside the kerogen core broke to form alkyl radicals and the gain and loss of hydrogen radicals would generate normal alkane and alkene. Affected by steric hindrance, short-chain alkyl radicals $\left(\mathrm{C}_{14-}\right)$ were more likely to generate alkene than long-chain alkyl radicals $\left(\mathrm{C}_{15+}\right)$ [13].

The influence factors of oil shale pyrolysis included temperature, pressure, heating rate, atmosphere, and heating method. The effect of the atmosphere on the pyrolysis products of oil shale was attributed to that the atmosphere gas that participated in the chemical reaction during pyrolysis $[14,15]$. Nazzal and Williams found that the existence of water vapor could improve the yield of shale oil and increased the contents of nonpolar chain aliphatic hydrocarbons and aromatics in the shale oil [16]. Ma et al. proposed that the water medium reduced the energy required for kerogen cracking because of swelling effect and promoted the generation and release of hydrocarbons. It could reduce the temperature of hydrocarbon generation by about $120^{\circ} \mathrm{C}$ during pyrolysis of oil shale, compared with anhydrous pyrolysis [17]. Whitelaw et al. pointed out that the gas yield during the pyrolysis of oil shale under high-pressure hydrous conditions was $1 / 3$ of that under anhydrous conditions. Under high-pressure anhydrous conditions, the pyrolysis oil remained in the oil shale and hardly discharged, resulting in cracking into a large amount of hydrocarbon gas. Under hydrous conditions, $80 \%$ of the pyrolysis oil could be discharged and the oil yield was higher. The swelling effect of water had a strong diffusion ability and permeability, which was conducive to the formation of pores in kerogen. The pyrolysis oil and gas products could release quickly, reducing the secondary cracking of oil [18]. In addition, the intro- duction of $\mathrm{CO}_{2}$ during the pyrolysis process of oil shale could improve the yield of pyrolysis oil and the carbon number distribution of pyrolysis oil was more concentrated, improving the quality of pyrolysis oil [19]. Jamil et al. showed that $\mathrm{CO}_{2}$ could promote the cracking of benzene rings, methyl groups, and methylene groups in coal and weaken the interaction reaction between $\mathrm{H}$ and char, thus having a positive effect on the yield and quality of coal tar [20]. Liu et al. found that in the $\mathrm{CO}_{2}$ atmosphere, the yield of char during devolatilization was lower than that in the $\mathrm{N}_{2}$ atmosphere. This was attributed to that the gasification reaction of $\mathrm{CO}_{2}$ with tar and char occurred. The char formed in the $\mathrm{CO}_{2}$ atmosphere was accompanied by a rough surface, which exposed more pores in the char matrix. It had a lower degree of graphitization and a smaller aromatic ring system [21].

In summary, water vapor and $\mathrm{CO}_{2}$ had positive effects on the pyrolysis and thermal conversion of organic matter in oil shale or coal. However, the above studies were all focused on the effect of a single atmosphere on the characteristics of pyrolysis products and were not systematic. Few studies investigated the effect of the two atmospheres on the pyrolysis behavior and product quality of oil shale systematically, compared with that of the inert atmosphere. Therefore, in this paper, the pyrolysis process, pyrolysis characteristic parameters, pyrolysate distribution, and oil quality of Jimusar oil shale in three atmospheres were studied. The characteristics of pyrolysis oil were determined using the GC-MS and elemental analyzer, and the pore characteristic of solid residual was analyzed by $\mathrm{N}_{2}$ adsorption experiments. These would provide theoretical references and technical guidance for the clean and efficient utilization of oil shale.

\section{Experimental Section}

2.1. Oil Shale Samples. The Xinjiang Jimusar oil shale (JM) was adopted in the experiment. The samples were crushed, sieved to 100 mesh, and packaged for later use. The proximate analysis and ultimate analysis (GB/T 212-2008 and GB/T 31391-2015) results of JM oil shale were shown in Table 1 . It could be seen in Table 1 that there were higher volatile contents, lower moisture, and fixed carbon contents in JM oil shale. And, the atomic ratios of $\mathrm{H} / \mathrm{C}$ and $\mathrm{O} / \mathrm{C}$ were 1.53 and 0.09 , respectively; thus, the kerogen type belonged to type I, which had a good hydrocarbon generation potential [22].

2.2. Pyrolysis Experiment. The JM oil shale pyrolysis experiment was carried out in the HYLZ-2 pyrolysis experiment system, which consisted of the gas supply device, pyrolysis device, temperature control device, and condensation device, as shown in Figure 1. The experimental sample was about $50 \mathrm{~g}$. The temperature range was from room temperature to $550^{\circ} \mathrm{C}$, and the heating rate was $10^{\circ} \mathrm{C} / \mathrm{min}$. The pyrolysis atmospheres were set to $\mathrm{N}_{2}$, water vapor, and $\mathrm{CO}_{2}$, respectively, and the carrier gas flow was $100 \mathrm{ml} / \mathrm{min}$. After the pyrolysis experiment, the pyrolysis products were collected 
TABLE 1: The proximate analysis and ultimate analysis of JM.

\begin{tabular}{lcccccccc}
\hline \multirow{2}{*}{ Sample } & \multicolumn{3}{c}{ Proximate analysis $\left(w_{\text {ad }} \%\right)$} & \multicolumn{3}{c}{ Ultimate analysis $\left(w_{a d} \%\right)$} \\
& $M$ & $A$ & $V$ & $F C$ & $C$ & $H$ & $O$ & $N$ \\
\hline JM & 0.15 & 52.05 & 43.86 & 3.94 & 39.31 & 5.02 & 4.69 & 1.39 \\
\hline
\end{tabular}

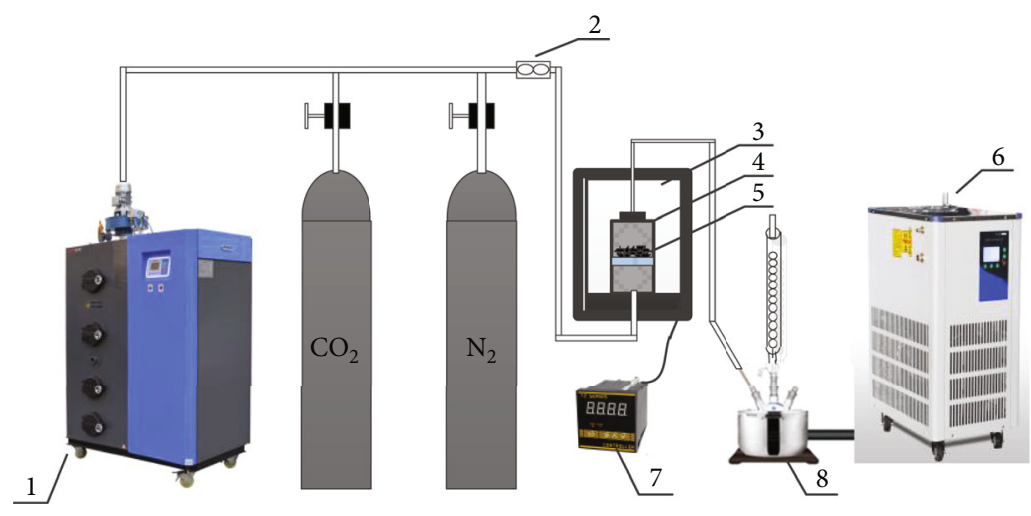

FIgURE 1: Pyrolysis experiment system of JM oil shale; 1: water vapor generator; 2: gas flow meter; 3: pyrolysis furnace; 4: pyrolysis reactor; 5: oil shale sample; 6: cooling water circulation device; 7: temperature controller; 8: condensing device.

and the yields of gas, liquid, and solid products were calculated.

2.3. TG Experiment. The thermogravimetry experiments (TG) of JM oil shale in different atmosphere were carried out in a German NETZCSH STA 449 F3 thermogravimetry analyzer. The oil shale samples used in TG experiments were $10 \pm 0.1 \mathrm{mg}$. The experimental temperature was from room temperature to $900^{\circ} \mathrm{C}$ with a heating rate of $10^{\circ} \mathrm{C} / \mathrm{min}$. The pyrolysis atmospheres were set to $\mathrm{N}_{2}$, water vapor, and $\mathrm{CO}_{2}$, and the flow rate of carrier gas was $100 \mathrm{ml} / \mathrm{min}$. And, the TG and DTG curves obtained from thermogravimetry experiments were employed to calculate the pyrolysis characteristic parameters and analyze the pyrolysis behavior of JM oil shale.

2.4. Pyrolysis Parameters. To further study the pyrolysis behavior of JM oil shale, the following pyrolysis characteristic parameters were introduced:

(1) The initial precipitation temperature of volatiles $\left(T_{v}\right)$ was the corresponding temperature when the weight loss rate of oil shale volatiles is the lowest after the drying and degassing stages [23]

(2) The half-peak width $\left(\Delta T_{1 / 2}\right)$ was the temperature range when $(d w / d t) /(d w / d t)_{\max }=1 / 2$, which was used to evaluate the concentration degree of oil shale volatile precipitation

(3) The comprehensive release characteristic index of the volatile $(D)$ was used to indicate the release performance of volatiles in the oil shale [24]

$$
D=\frac{(d w / d t)_{\max } \times(d w / d t)_{\text {mean }}}{T_{v} \times T_{\max } \times \Delta T_{1 / 2}}
$$

where $(d w / d t)_{\max }$ is the maximum weight loss rate during oil shale pyrolysis, $\% / \mathrm{min},(d w / d t)_{\text {mean }}$ is the average weight loss rate during oil shale pyrolysis, $\% / \mathrm{min}, T_{v}$ is the initial precipitation temperature of volatiles during oil shale pyrolysis, ${ }^{\circ} \mathrm{C}, T_{\max }$ is the temperature corresponding to the maximum weight loss rate, ${ }^{\circ} \mathrm{C}$, and $\Delta T_{1 / 2}$ is the half-peak width, ${ }^{\circ} \mathrm{C}$.

2.5. Characterization of Pyrolysis Oil. The pyrolysis oil was firstly diluted with dichloromethane, and its component was determined by an Agilent 7890 gas chromatograph with an automatic sampler and a $5795 \mathrm{~N}$ mass spectrometer (GC-MS). And then, the components were matched with the database (NIST08 and NIST08s) for qualitative analysis and their relative contents were calculated by the area normalization method.

Furthermore, the contents of $\mathrm{C}, \mathrm{H}, \mathrm{O}, \mathrm{N}$, and $\mathrm{S}$ elements in the pyrolysis oil were determined by using the Vario EL cube elemental analyzer produced by Elementar Company in Germany. The raw materials fully burned in the elemental analyzer, and the generated mixed gas entered a special chromatographic column for separation. The concentration of each gas was analyzed and measured through a thermal conductivity detector, which was then converted into the element content.

2.6. Pore Characterization of Solid Residues. The specific surface area and pore structure were measured by the ASAP2000-type-specific surface area and pore size analyzer. The $\mathrm{N}_{2}$ physisorption experiments were performed at $-196^{\circ} \mathrm{C}$ to obtain the adsorption capacity of the solid residuals. The specific surface area was calculated by the Brunauer-Emmett-Teller (BET) equation. The pore volume was determined by the desorption branch of isotherms using Barrett-Joyner-Halenda (BJH) methods. The total pore 


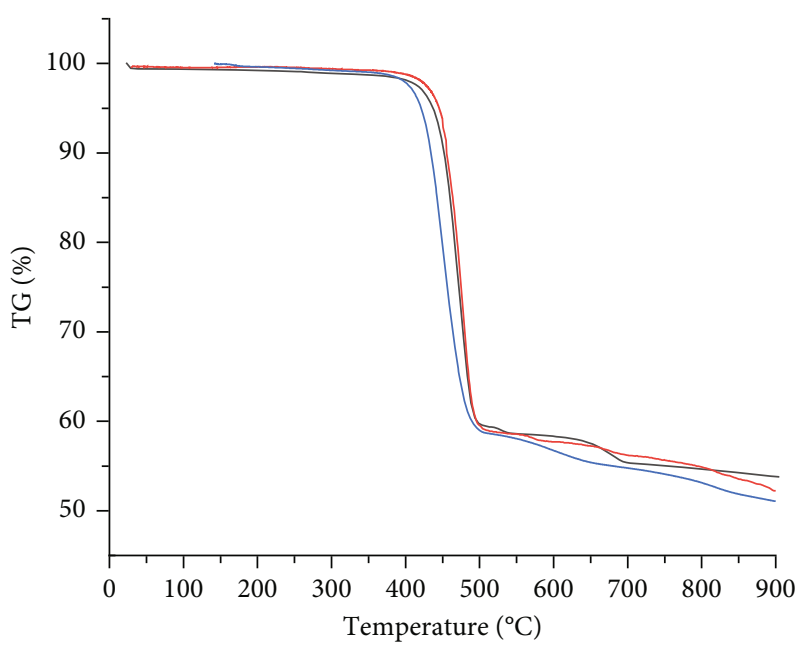

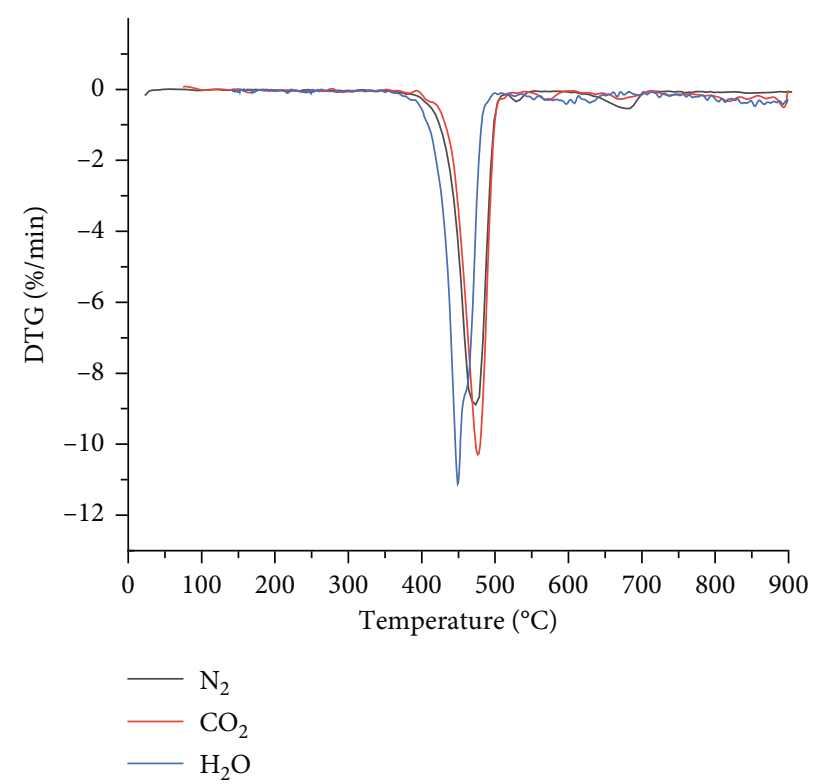

(b)

FIgURE 2: TG-DTG curves of JM in different atmospheres.

volume was calculated from the $\mathrm{N}_{2}$ adsorption capacity at $P / P_{0}=0.996$.

\section{Results and Discussion}

3.1. Pyrolysis Behavior of Oil Shale. Figure 2 showed the TG-DTG curves of JM oil shale heated from room temperature to $900^{\circ} \mathrm{C}$ with a heating rate of $10^{\circ} \mathrm{C} / \mathrm{min}$ in $\mathrm{N}_{2}, \mathrm{CO}_{2}$, and $\mathrm{H}_{2} \mathrm{O}$ atmospheres. It could be seen in Figure 2(a) that with the increase of temperature, the thermal degradation of oil shale occurred during pyrolysis, and the weight loss behavior was different in various atmospheres. The weight losses of oil shale during pyrolysis in $\mathrm{CO}_{2}$ and $\mathrm{H}_{2} \mathrm{O}$ atmospheres were higher than that in the $\mathrm{N}_{2}$ atmosphere, which indicated that the existence of $\mathrm{CO}_{2}$ and $\mathrm{H}_{2} \mathrm{O}$ promoted the cracking of kerogen and the release of volatiles in oil shale. And, the effect of the $\mathrm{H}_{2} \mathrm{O}$ atmosphere performed better than that of the $\mathrm{CO}_{2}$ atmosphere. As depicted in Figure 2(b), there was a significant weight loss peak of oil shale at $350-550^{\circ} \mathrm{C}$, the organic kerogen in oil shale began to decompose and the unstable bridge bonds broke; thus, a large number of free radicals were generated and released. The free radicals combined with each other to form volatile oil and gas, and the macromolecular polycyclic aromatic hydrocarbons polymerized into semichar [25]. Compared with the $\mathrm{N}_{2}$ atmosphere, the weight loss rate of JM oil shale during pyrolysis in $\mathrm{CO}_{2}$ and $\mathrm{H}_{2} \mathrm{O}$ atmospheres increased. Meanwhile, $\mathrm{H}_{2} \mathrm{O}$ made the pyrolysis process of oil shale move to a low-temperature zone, so that the oil shale could be pyrolyzed at a lower temperature, while the opposite trend was observed in the $\mathrm{CO}_{2}$ atmosphere. Furthermore, at the temperature of $650-700^{\circ} \mathrm{C}$, the second weight loss peak was the decomposition of carbonates [26] and this peak was not detected in both $\mathrm{CO}_{2}$ and $\mathrm{H}_{2} \mathrm{O}$ atmospheres, indicating that $\mathrm{CO}_{2}$ and $\mathrm{H}_{2} \mathrm{O}$ inhibited the decomposition of car- bonates. At the final temperature, the order of weight loss of oil shale was $\mathrm{H}_{2} \mathrm{O}>\mathrm{CO}_{2}>\mathrm{N}_{2}$.

3.2. Pyrolysis Characteristic Parameters of Oil Shale. Table 2 listed the pyrolysis characteristic parameters obtained from the TG-DTG curves of JM oil shale. As shown in Table 2, the existence of high-temperature water vapor reduced the initial precipitation temperature of pyrolysis volatiles and advanced the release of pyrolysis oil and gas. Because the external high-temperature water vapor brought additional heat and energy into the pyrolysis system. In the $\mathrm{H}_{2} \mathrm{O}$ atmosphere, the initial precipitation temperature $\left(T_{v}\right)$ of the pyrolysis volatiles was reduced by $17^{\circ} \mathrm{C}$ compared with the $\mathrm{N}_{2}$ atmosphere and the peak temperature corresponding to the maximum weight loss rate $\left(T_{\max }\right)$ was reduced by $24^{\circ} \mathrm{C}$, so that the pyrolysis reaction of oil shale could be carried out at a lower temperature, while in the $\mathrm{CO}_{2}$ atmosphere, the initial precipitation temperature of pyrolysis volatiles increased by $20^{\circ} \mathrm{C}$ and the peak temperature increased slightly, which made the pyrolysis reaction move to the high-temperature region. The maximum reaction rate and average reaction rate during pyrolysis of oil shale were both increased in the atmosphere of $\mathrm{CO}_{2}$ and $\mathrm{H}_{2} \mathrm{O}$, owing to the fact that high-temperature $\mathrm{CO}_{2}$ and $\mathrm{H}_{2} \mathrm{O}$ promoted the breaking and polymerization of chemical bonds in kerogen, resulting in heterogeneous reactions of $\mathrm{CO}_{2}$ and $\mathrm{H}_{2} \mathrm{O}$ with organic matter and homogeneous reactions with volatiles [27]. Furthermore, the presence of $\mathrm{CO}_{2}$ and $\mathrm{H}_{2} \mathrm{O}$ both decreased the $\Delta T_{1 / 2}$ values and narrowed the half-peak width of the oil shale pyrolysis and the pyrolysis oil and gas released in a smaller temperature range, making the pyrolysis reaction more concentrated. The comprehensive release characteristic index of volatiles $(D)$ was an important index to evaluate the reactivity of oil shale pyrolysis. The larger the $D$ value, the faster and more concentrated the 
TABle 2: Pyrolysis characteristic parameters of JM oil shale.

\begin{tabular}{lcccccc}
\hline Atmospheres & $T_{v}\left({ }^{\circ} \mathrm{C}\right)$ & $T_{\max }\left({ }^{\circ} \mathrm{C}\right)$ & $(d w / d t)_{\max } /(\% / \min )$ & $(d w / d t)_{\text {mean }} /(\% / \mathrm{min})$ & $\Delta T_{1 / 2}\left({ }^{\circ} \mathrm{C}\right)$ & $D \times 107 /\left(\%^{2} \cdot \min ^{-2} \cdot{ }^{\circ} \mathrm{C}^{-3}\right)$ \\
\hline $\mathrm{N}_{2}$ & 378.5 & 473.5 & 8.87 & 0.48 & 39.2 & 6.06 \\
$\mathrm{CO}_{2}$ & 398.7 & 476.6 & 10.29 & 0.56 & 33.5 & 9.05 \\
$\mathrm{H}_{2} \mathrm{O}$ & 361.5 & 449.1 & 11.12 & 0.64 & 33.7 & 12.99 \\
\hline
\end{tabular}

release rate of volatiles and the better the pyrolysis reactivity of oil shale [28]. In the $\mathrm{CO}_{2}$ and $\mathrm{H}_{2} \mathrm{O}$ atmospheres, the comprehensive release characteristic indices of pyrolysis volatiles increased by $49.34 \%$ and $114.35 \%$, respectively, compared with the $\mathrm{N}_{2}$ atmosphere. Therefore, the $\mathrm{CO}_{2}$ and $\mathrm{H}_{2} \mathrm{O}$ atmospheres promoted the release of volatiles and effectively improved the pyrolysis reactivity of oil shale.

3.3. Product Distribution of Oil Shale Pyrolysis. Figure 3 exhibited the distribution of pyrolysis products of JM oil shale in different atmospheres. As was displayed in Figure 3, the pyrolytic water contents were less than $1 \%$ in different atmospheres, which indicated that the pyrolytic water content of JM oil shale was less, and the atmosphere has little effect on the yield of pyrolytic water. Compared with the $\mathrm{N}_{2}$ atmosphere, the presence of $\mathrm{CO}_{2}$ and $\mathrm{H}_{2} \mathrm{O}$ both improved the yield of pyrolysis oil and the effect of the $\mathrm{H}_{2} \mathrm{O}$ atmosphere performed better than the $\mathrm{CO}_{2}$ atmosphere. In the $\mathrm{H}_{2} \mathrm{O}$ atmosphere, the yield of pyrolysis oil increased by $41.42 \%$, while that in the $\mathrm{CO}_{2}$ atmosphere increased by $19.67 \%$. This is attributed to that at high temperature, water vapor could provide more hydrogen, which quickly combined with the pyrolysis oil cracking fragments and promoted the generation and release of pyrolysis oil [29]. In the $\mathrm{CO}_{2}$ atmosphere, $\mathrm{CO}_{2}$ and $\mathrm{CH}_{4}$ underwent a reforming reaction under the catalysis of char and intrinsic minerals to generate more $\bullet \mathrm{CH}$ and $\bullet \mathrm{H}$ free radicals, thereby increasing the yield of pyrolysis oil [30]. In $\mathrm{CO}_{2}$ and $\mathrm{H}_{2} \mathrm{O}$ atmospheres, they promoted the devolatilization behavior of oil shale and inhibited the polymerization of pyrolysis oil macromolecular fragments into char, resulting in a decrease in the yield of solid residues. For the pyrolysis gas yield, after excluding the error caused by the carrier gas, the yields of pyrolysis gas in both $\mathrm{CO}_{2}$ and $\mathrm{H}_{2} \mathrm{O}$ atmospheres decreased slightly, which maybe because the presence of $\mathrm{CO}_{2}$ and $\mathrm{H}_{2} \mathrm{O}$ inhibited the generation of small-molecular gases in kerogen or the $\mathrm{H}_{2}, \mathrm{CO}, \mathrm{CO}_{2}$, and hydrocarbon gases in the pyrolysis gas participated in the reforming reaction of pyrolysis oil under the catalysis of coke and minerals [31].

\subsection{Analysis of Pyrolysis Oil}

3.4.1. Component Analysis. The chemical components of pyrolysis oil obtained from pyrolysis of JM oil shale in different atmospheres were determined by GC-MS. The total ion chromatograms were shown in Figure 4. The chemical components of pyrolysis oil were classified into four categories, namely, alkane, alkene, aromatic hydrocarbons, and heteroatom compounds (containing $\mathrm{O}, \mathrm{S}$, and $\mathrm{N}$ ), and the results were listed in Table 3. It could be seen in Figure 4 and Table 3 that normal alkane and normal alkene with the same

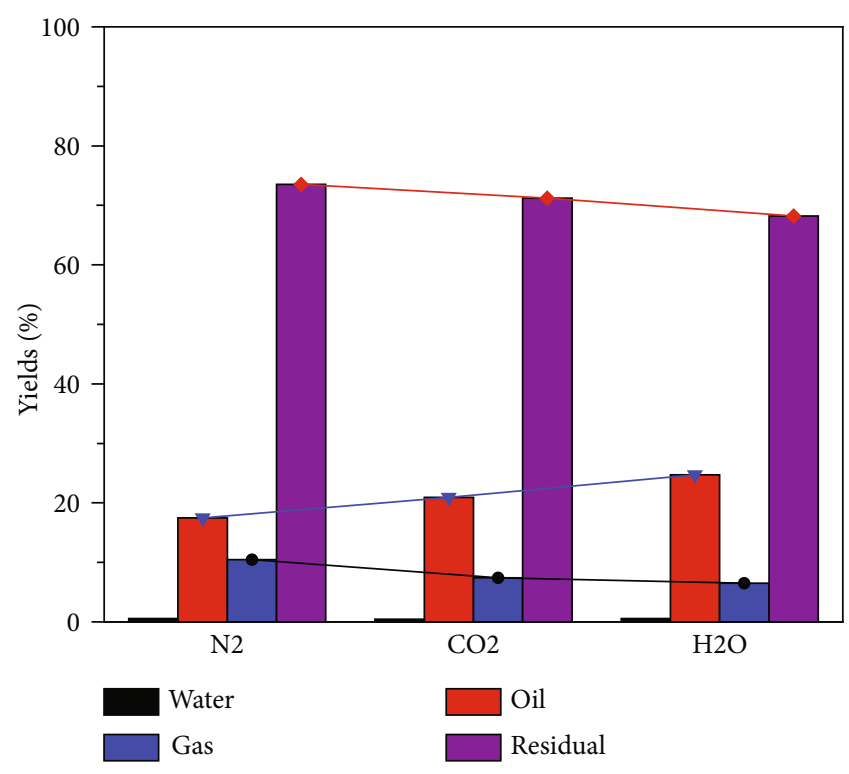

Figure 3: Product distribution of JM oil shale in different atmospheres.

carbon number appeared in pairs, forming the bimodal distribution of aliphatic hydrocarbons [32]. The relative contents of aliphatic hydrocarbons in the pyrolysis oil in different atmospheres were more than $90 \%$, which was in a dominant role, while the relative content of aromatic hydrocarbons and heteroatom compounds was less [33]. The existence of $\mathrm{CO}_{2}$ delayed the precipitation of volatiles in the pyrolysis process of oil shale. Therefore, $\mathrm{CO}_{2}$ mainly participated in the secondary reaction of pyrolysis volatiles. Compared with the $\mathrm{N}_{2}$ atmosphere, $\mathrm{CO}_{2}$ increased the relative content of alkene and decreased the relative content of alkane, because the presence of $\mathrm{CO}_{2}$ prevented methyl radicals from accepting hydrogen radicals, thereby reducing the content of alkane, while $\mathrm{CO}_{2}$ participated in the addition reaction of methyl radicals and lost a hydrogen radical, increasing the content of alkene. The effect of water vapor on the content of alkane and alkene in pyrolysis oil was opposite to that of $\mathrm{CO}_{2}$. This was because water vapor provided more $\bullet \mathrm{H}$ free radicals at high temperature under the effect of inherent minerals, and $\bullet \mathrm{H}$ free radicals combined with methyl radicals to generate more alkane and, at the same time, hydrogen radicals also inhibited the formation of alkene $[29,32]$.

Furthermore, both water vapor and $\mathrm{CO}_{2}$ atmospheres increased the relative content of aromatic hydrocarbons in the pyrolysis oil. This was because they both promoted the cracking of macromolecular polycyclic aromatic hydrocarbons, which not only was beneficial in generating BTEX 


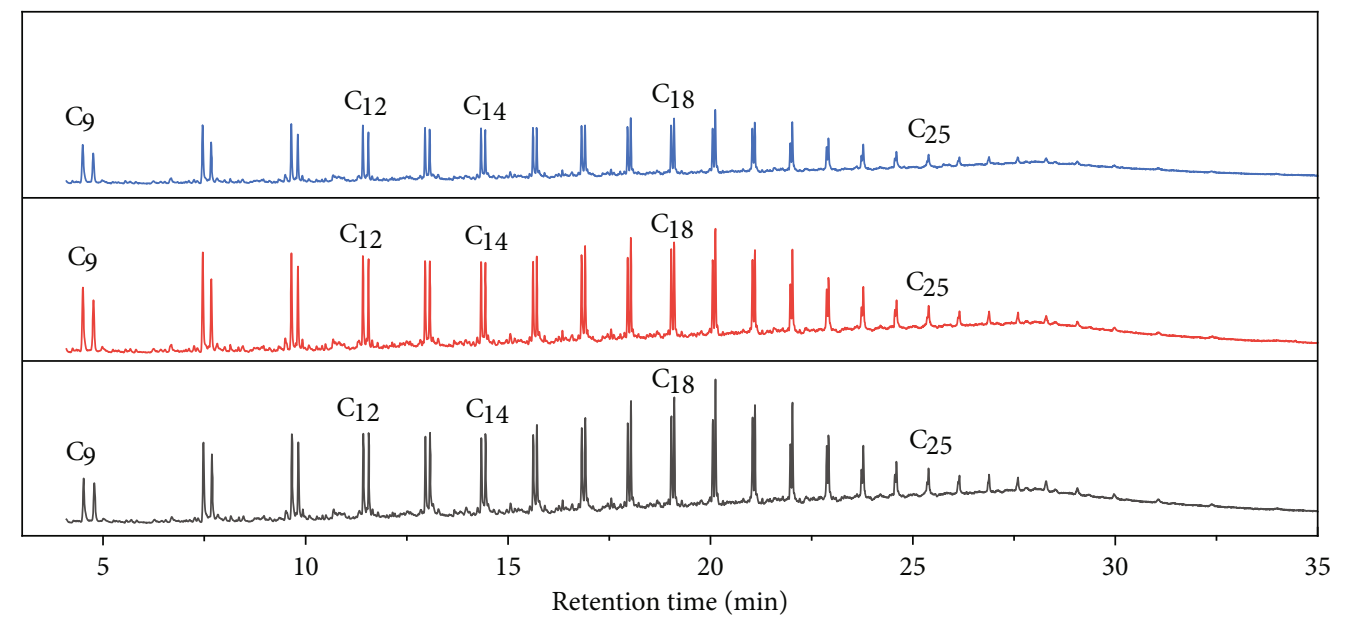

$-\mathrm{N}_{2}$
$-\mathrm{CO}_{2}$
$-\mathrm{H}_{2} \mathrm{O}$

FIGURE 4: Total ion chromatograms of pyrolysis oil in different atmospheres.

TABLE 3: Chemical components of pyrolysis oil in different atmospheres.

\begin{tabular}{lcccc}
\hline Atmosphere & $\begin{array}{c}\text { Alkane } \\
(\%)\end{array}$ & $\begin{array}{c}\text { Alkene } \\
(\%)\end{array}$ & $\begin{array}{c}\text { Aromatic } \\
\text { hydrocarbon (\%) }\end{array}$ & $\begin{array}{c}\text { Heteroatom } \\
(\%)\end{array}$ \\
\hline $\mathrm{N}_{2}$ & 55.96 & 36.94 & 3.67 & 3.43 \\
$\mathrm{CO}_{2}$ & 53.46 & 40.05 & 4.53 & 1.96 \\
$\mathrm{H}_{2} \mathrm{O}$ & 59.20 & 34.03 & 5.14 & 1.63 \\
\hline
\end{tabular}

and PAHs with smaller molecular hydrocarbons but also inhibited the polymerization into char. Also, water vapor and $\mathrm{CO}_{2}$ could reduce the relative content of heteroatom compounds in the pyrolysis oil. Therefore, both atmospheres have better effects on the removal of heteroatom compounds in the pyrolysis oil and improved the quality of pyrolysis oil.

3.4.2. Carbon Number Distribution. To further investigate the quality of pyrolysis oil in different atmospheres, considering that the relative content of aliphatic hydrocarbons in the pyrolysis oil accounted for more than $90 \%$, the aliphatic hydrocarbons were divided into three parts according to the carbon number, namely, the short-chain light components $\left(\mathrm{C}_{8}-\mathrm{C}_{12}\right)$, the mid-chain medium components $\left(\mathrm{C}_{13}-\mathrm{C}_{18}\right)$, and the long-chain heavy components $\left(\mathrm{C}_{19}-\mathrm{C}_{25}\right.$ and $\left.\mathrm{C}_{26+}\right)$ and the results were exhibited in Figure 5 . It could be seen in Figure 5 that the sum of the relative contents of shortchain and mid-chain aliphatic hydrocarbons played a dominant role in pyrolysis oil, exceeding $70 \%$. Both water vapor and $\mathrm{CO}_{2}$ atmospheres increased the relative content of short-chain aliphatic hydrocarbons in the pyrolysis oil, and the order of the relative content of short-chain aliphatic hydrocarbons was $\mathrm{H}_{2} \mathrm{O}>\mathrm{CO}_{2}>\mathrm{N}_{2}$. The relative contents of mid-chain and long-chain aliphatic hydrocarbons decreased, and the relative content of heavy oil above $C_{26}$ decreased to zero in the water vapor atmosphere, because

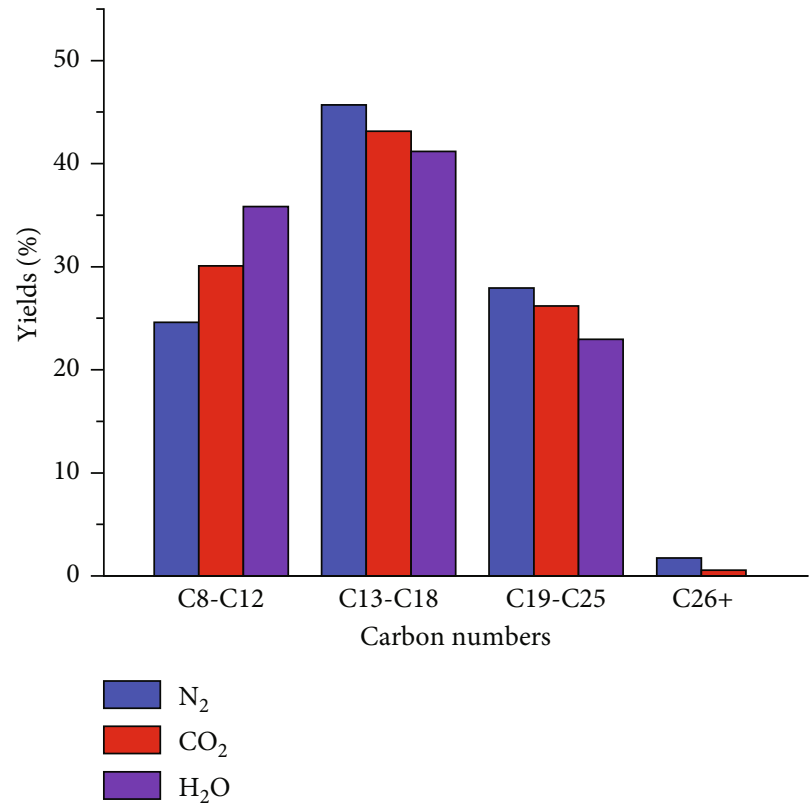

Figure 5: Carbon number distribution of aliphatic hydrocarbons in pyrolysis oil in different atmospheres.

water vapor and $\mathrm{CO}_{2}$ promoted the cracking of long-chain aliphatic hydrocarbons into short-chain aliphatic hydrocarbons at high temperatures and water vapor and $\mathrm{CO}_{2}$ underwent a reforming reaction with the heavy oil, which increased the relative content of light components. Relevant literature showed that in high-temperature atmospheres of $\mathrm{CH}_{4}-\mathrm{CO}_{2}$ and $\mathrm{CO}-\mathrm{H}_{2} \mathrm{O}$, more $\bullet \mathrm{H}$ free radicals could be provided under the effect of the catalyst and the reforming reaction was coupled with the pyrolysis reaction. Also, the $\bullet H$ free radicals had strong attack ability, which made the pyrolysis oil underwent hydrogenation reaction and more heavy 
TABLE 4: Elemental analysis of pyrolysis oil in different atmospheres.

\begin{tabular}{lccccccc}
\hline Atmospheres & $\mathrm{C} \%$ & $\mathrm{H} \%$ & $\mathrm{O} \%$ & $\mathrm{~N} \%$ & $\mathrm{~S} \%$ & $\mathrm{H} / \mathrm{C}$ & $\mathrm{O} / \mathrm{C}$ \\
\hline $\mathrm{N}_{2}$ & 85.16 & 10.42 & 2.97 & 1.61 & 0.18 & 1.47 & 0.03 \\
$\mathrm{CO}_{2}$ & 85.47 & 11.23 & 2.16 & 1.03 & 0.12 & 1.58 & 0.02 \\
$\mathrm{H}_{2} \mathrm{O}$ & 84.24 & 13.72 & 1.28 & 0.95 & 0.08 & 1.95 & 0.01 \\
\hline
\end{tabular}

oil cracked into light oil $[34,35]$. Therefore, the water vapor and $\mathrm{CO}_{2}$ atmospheres made the pyrolysis oil lighter and improved its quality and the effect of water vapor was better than that of $\mathrm{CO}_{2}$.

3.4.3. Elemental Analysis. Table 4 listed the $\mathrm{C}, \mathrm{H}, \mathrm{O}, \mathrm{N}$, and $\mathrm{S}$ elemental analysis results of pyrolysis oil in different atmospheres. It could be seen in Table 4 that both $\mathrm{CO}_{2}$ and $\mathrm{H}_{2} \mathrm{O}$ atmospheres increased the content of $\mathrm{H}$ and decreased the content of $\mathrm{O}$ in the pyrolysis oil, indicating that $\mathrm{CO}_{2}$ and $\mathrm{H}_{2} \mathrm{O}$ promoted the conversion of $\mathrm{H}$ from the oil shale to the pyrolysis oil, while inhibiting the conversion of $\mathrm{O}$. They both participated in the secondary reforming reaction of the pyrolysis oil, thereby increasing the $\mathrm{H} / \mathrm{C}$ ratio and decreasing the $\mathrm{O} / \mathrm{C}$ ratio of the pyrolysis oil, and the effect of the $\mathrm{H}_{2} \mathrm{O}$ atmosphere was better than that of the $\mathrm{CO}_{2}$ atmosphere. Compared with the $\mathrm{N}_{2}$ atmosphere, the water vapor atmosphere increased the $\mathrm{H} / \mathrm{C}$ ratio of the pyrolysis oil by $32.65 \%$. Therefore, the quality of pyrolysis oil in the $\mathrm{CO}_{2}$ and $\mathrm{H}_{2} \mathrm{O}$ atmospheres was better than that in the $\mathrm{N}_{2}$ atmosphere, which increased the content of aliphatic hydrocarbons in the pyrolysis oil and stored more energy [36]. Furthermore, the $\mathrm{CO}_{2}$ atmosphere slightly increased the content of $\mathrm{C}$ in the pyrolysis oil, while the $\mathrm{H}_{2} \mathrm{O}$ atmosphere showed the opposite trend. The water vapor inhibited the conversion of $\mathrm{C}$ from the oil shale to the pyrolysis oil, while $\mathrm{CO}_{2}$ promoted the conversion of $\mathrm{C}$. Meanwhile, the $\mathrm{CO}_{2}$ atmosphere also provided a carbon source, which underwent the secondary reaction with the pyrolysis volatiles to bring part of carbon into the pyrolysis oil.

In the atmospheres of $\mathrm{CO}_{2}$ and $\mathrm{H}_{2} \mathrm{O}$, the content of heteroatoms such as $\mathrm{N}$ and $\mathrm{S}$ in the pyrolysis oil decreased, indicating that $\mathrm{CO}_{2}$ and $\mathrm{H}_{2} \mathrm{O}$ had a positive effect on the removal of heteroatom compounds from the pyrolysis oil, so that the quality of the pyrolysis oil was better than that in the $\mathrm{N}_{2}$ atmosphere. And the effect of water vapor was better than that of $\mathrm{CO}_{2}$, which was consistent with the previous chemical component analysis results. This was because the heteroatom compounds such as $\mathrm{N}$ and $\mathrm{S}$ in the pyrolysis oil mainly existed in the form of aromatic rings, such as thiophene and pyridine [37]. These heteroatom aromatic rings underwent hydrogenation reaction in the hydrogen-rich environment of high-temperature water vapor, releasing $\mathrm{N}$ and $\mathrm{S}$ in the form of light gases, such as $\mathrm{NH}_{4}$ and $\mathrm{H}_{2} \mathrm{~S}$.

3.5. Pores Analysis of Solid Residues. Table 5 listed the specific surface area and pore volume of solid residues obtained from the pyrolysis of oil shale in different atmospheres. The results revealed that the specific surface area and pore volume of pyrolysis residue of oil shale were small, which was
TABLE 5: The specific surface area and pore volume of solid residues in different atmospheres.

\begin{tabular}{lccc}
\hline Atmosphere & $\mathrm{N}_{2}$ & $\mathrm{CO}_{2}$ & $\mathrm{H}_{2} \mathrm{O}$ \\
\hline Specific surface area $\left(\mathrm{m}^{2} / \mathrm{g}\right)$ & 74.40 & 83.46 & 111.53 \\
Pore volume $\left(\times 10^{-3} \mathrm{ml} / \mathrm{g}\right)$ & 198.10 & 269.11 & 291.98 \\
\hline
\end{tabular}

due to the high ash content of oil shale. With the progress of pyrolysis reaction, the volatile oil and gas gradually precipitated and released and the pores and channels were generated in the particles of oil shale, which were gradually deepened. When the $\mathrm{CO}_{2}$ and water vapor existed during pyrolysis, the specific surface area and pore volume of pyrolysis residue increased. Especially, in the $\mathrm{H}_{2} \mathrm{O}$ atmosphere, the specific surface area and pore volume of pyrolysis residue increased by $49.91 \%$ and $47.39 \%$, compared with those in the $\mathrm{N}_{2}$ atmosphere. This was attributed to the fact that high-temperature $\mathrm{CO}_{2}$ and water vapor could promote the precipitation of volatile gas and oil and gradually enlarge the internal pores and channels of solid particles. Therefore, the high-temperature $\mathrm{CO}_{2}$ and water vapor had the ability of pore expansion in the pyrolysis process of oil shale, which could enhance the mass and heat transfer efficiency. They could make the pyrolysis volatile easier to precipitate and conducive to the formation of oil and gas. Water pressure and gas pressure had a significant impact on the structure of pores and channels in the oil shale particles, which further affected the seepage and migration of oil and gas in solid residues [38-41]. At the same time, high-temperature water vapor had swelling effect, which could easily carry volatile oil and gas out of the internal pores and channels of particles. Therefore, the specific surface area and pore volume of the pyrolysis residue in the $\mathrm{H}_{2} \mathrm{O}$ atmosphere were higher than those in $\mathrm{CO}_{2}$ and $\mathrm{N}_{2}$ atmospheres and the order of pore expansion capacity was $\mathrm{H}_{2} \mathrm{O}>\mathrm{CO}_{2}>\mathrm{N}_{2}$.

\section{Conclusions}

(1) The presence of $\mathrm{H}_{2} \mathrm{O}$ and $\mathrm{CO}_{2}$ promoted the cracking of oil shale and the release of volatiles, and the weight loss and weight loss rate were both increased, compared with those in the $\mathrm{N}_{2}$ atmosphere. And, $\mathrm{H}_{2} \mathrm{O}$ made the pyrolysis process of oil shale move to low-temperature zone

(2) Compared with the $\mathrm{N}_{2}$ atmosphere, $\mathrm{H}_{2} \mathrm{O}$ reduced the initial precipitation temperature of volatiles of oil shale by $17^{\circ} \mathrm{C}$. In both the $\mathrm{H}_{2} \mathrm{O}$ and $\mathrm{CO}_{2}$ atmospheres, the $D$ indices of oil shale increased by $49.34 \%$ and $114.35 \%$, respectively, which significantly improved its pyrolysis reactivity

(3) Compared with the $\mathrm{N}_{2}$ atmosphere, both $\mathrm{H}_{2} \mathrm{O}$ and $\mathrm{CO}_{2}$ could improve the pyrolysis oil yield and the effect of $\mathrm{H}_{2} \mathrm{O}$ was better than $\mathrm{CO}_{2}$. Both atmospheres inhibited the polymerization of cracking oil fragments into macromolecule coke and also reduced the pyrolysis gas yield 
(4) High-temperature $\mathrm{H}_{2} \mathrm{O}$ provided more hydrogen radicals, which increased the yield of alkane and inhibited the formation of alkene in the pyrolysis oil, compared with the $\mathrm{N}_{2}$ atmosphere. And, it exhibited an opposite trend in the $\mathrm{CO}_{2}$ atmosphere

(5) Short- and medium-chain aliphatic hydrocarbons are dominant in pyrolysis oil of JM oil shale. The $\mathrm{CO}_{2}$ and $\mathrm{H}_{2} \mathrm{O}$ underwent reforming reactions with the heavy oil during pyrolysis, which increased the light components in pyrolysis oil. Both atmospheres improved the $\mathrm{H} / \mathrm{C}$ ratio and quality of pyrolysis oil, and the effect of $\mathrm{H}_{2} \mathrm{O}$ was better than that of $\mathrm{CO}_{2}$

(6) The $\mathrm{H}_{2} \mathrm{O}$ and $\mathrm{CO}_{2}$ atmospheres could facilitate the formation of a well-developed pore structure, thereby increasing the specific surface areas and pore volumes of solid residues

\section{Data Availability}

The experimental data used to support the findings of this study are included within the article.

\section{Conflicts of Interest}

The authors declare that they have no conflicts of interest.

\section{Acknowledgments}

This work was supported by the National Key Research and Development Program of China (2019YFA0705501), National Natural Science Foundation of China (51974191), China National Postdoctoral Program for Innovative Talents (Grant no. BX2021209), and China Postdoctoral Science Foundation (Grant no. 2021M692372).

\section{References}

[1] Y. He, G. Qi, X. Dou et al., "Research on organic nanopore adsorption mechanism and influencing factors of shale oil reservoirs," Geofluids, vol. 2021, 10 pages, 2021.

[2] R. Li, Z. Sun, J. He, Z. W. Liao, L. Li, and F. Qian, "Variations on reservoir parameters of oil shale deposits under periodic freeze-thaw cycles: laboratory tests," Geofluids, vol. 2021, 11 pages, 2021.

[3] Z. Chang, M. Chu, C. Zhang, S. Bai, H. Lin, and L. Ma, "Influence of inherent mineral matrix on the product yield and characterization from Huadian oil shale pyrolysis," Journal of Analytical and Applied Pyrolysis, vol. 130, pp. 269-276, 2018.

[4] Y. Lu, Y. Wang, Q. Wang, J. Zhang, Y. Zhao, and Y. Zhang, "Investigation on the catalytic effect of AAEMs on the pyrolysis characteristics of Changji oil shale and its kinetics," Fuel, vol. 267, p. 117287, 2020.

[5] H. Zheng, W. Shi, D. Ding, and C. Zhang, "Numerical simulation of in situ combustion of oil shale," Geofluids, vol. 2017, 9 pages, 2017.

[6] L. Yang and P. Li, "Evolution of the oil shale permeability under real-time high-temperature triaxial stress in the Jimusar area, Xinjiang," Geofluids, vol. 2021, 10 pages, 2021.
[7] M. Dai, Z. Yu, S. Fang, and X. Ma, "Behaviors, product characteristics and kinetics of catalytic co-pyrolysis spirulina and oil shale," Energy Conversion and Management, vol. 192, pp. 1$10,2019$.

[8] Y. Sun, F. Bai, B. Liu et al., "Characterization of the oil shale products derived via topochemical reaction method," Fuel, vol. 115, pp. 338-346, 2014.

[9] W. Wang, Y. Ma, S. Li, C. Yue, and J. Gao, "Effect of retorting temperature on the pyrolysis characteristic of Longkou oil shale," Geofluids, vol. 2021, 11 pages, 2021.

[10] X. Jiang, X. Han, and Z. Cui, "New technology for the comprehensive utilization of Chinese oil shale resources," Energy, vol. 32, no. 5, pp. 772-777, 2007.

[11] Y. Lu, Y. Wang, Y. Xu, Y. Li, W. Hao, and Y. Zhang, "Investigation of ash fusion characteristics and migration of sodium during co- combustion of Zhundong coal and oil shale," Applied Thermal Engineering, vol. 121, pp. 224-233, 2017.

[12] M. D. K. Rajeshwar and J. DuBow, "D.c. electrical conductivity of Green River oil shales," Nature, vol. 287, no. 5778, pp. 131133, 1980

[13] J. J. Li, D. Z. Tang, H. Xu et al., "Pyrolysis-gas chromatography Of the oil shale in Lucaogou Formation, Dahuangshan, Southern Junggar Basin," Petroleum Exploration and Development, vol. 35, no. 6, pp. 674-679, 2008.

[14] H. Jiang, L. Song, Z. Cheng et al., "Influence of pyrolysis condition and transition metal salt on the product yield and characterization via Huadian oil shale pyrolysis," Journal of Analytical and Applied Pyrolysis, vol. 112, pp. 230-236, 2015.

[15] F. Bai, Y. Sun, Y. Liu, and M. Guo, "Evaluation of the porous structure of Huadian oil shale during pyrolysis using multiple approaches," Fuel, vol. 187, pp. 1-8, 2017.

[16] J. M. Nazzal and P. T. Williams, "Influence of temperature and steam on the products from the flash pyrolysis of Jordan oil shale," International Journal of Energy Research, vol. 26, no. 14, pp. 1207-1219, 2002.

[17] Y. Ma, S. Li, J. Wang, and C. Fang, "Kinetics of oil shale pyrolysis under saturated aqueous medium," CIESC Journal, vol. 61, no. 9, pp. 2474-2479, 2010.

[18] P. Whitelaw, C. N. Uguna, L. A. Stevens et al., "Shale gas reserve evaluation by laboratory pyrolysis and gas holding capacity consistent with field data," Nature Communications, vol. 10, no. 1, p. 3659, 2019.

[19] J. D. Tucker, B. Masri, and S. Lee, "A comparison of retorting and supercritical extraction techniques on El-Lajjun oil shale," Energy Sources, vol. 22, no. 5, pp. 453-463, 2000.

[20] K. Jamil, J. Hayashi, and C. Li, "Pyrolysis of a Victorian brown coal and gasification of nascent char in $\mathrm{CO}_{2}$ atmosphere in a wire-mesh reactor," Fuel, vol. 83, no. 7-8, pp. 833-843, 2004.

[21] Y. Liu, Y. Guan, and K. Zhang, "Gasification reactivity and morphology of coal chars formed in $\mathrm{N}-2$ and $\mathrm{CO} 2$ atmospheres," Chemical Papers, vol. 72, no. 8, pp. 2045-2054, 2018.

[22] X. Liu, D. Luo, J. Xiong, and L. Liang, "Construction of the average molecular modeling of the kerogen from the Longmaxi formation," Chemical Industry and Engineering Progress, vol. 36, no. 2, pp. 530-537, 2017.

[23] P. H. Qiu, Y. Zhao, X. Y. Chen, J. J. Xu, F. L. X. Du YW, and S. Z. Sun, "Effects of alkali and alkaline earth metallic species on pyrolysis characteristics and kinetics of Zhundong coal," Journal of Fuel Chemistry and Technology, vol. 10, pp. 11781189, 2014 
[24] C. Xiaoping, G. Lifeng, H. Xiaoqiang, Z. Changsui, and L. Daoyin, "Pyrolysis characteristics and ash fusion property of sludge and blended fuel of sludge and coal," Journal of Southeast University, vol. 38, no. 6, pp. 1038-1043, 2008.

[25] M. Liu, J. Yang, Y. Yang et al., "The radical and bond cleavage behaviors of 14 coals during pyrolysis with 9,10-dihydrophenanthrene," Fuel, vol. 182, pp. 480-486, 2016.

[26] L. Pan, F. Dai, G. Li, and S. Liu, "A TGA/DTA-MS investigation to the influence of process conditions on the pyrolysis of Jimsar oil shale," Energy, vol. 86, pp. 749-757, 2015.

[27] Q. Chang, R. Gao, H. Li et al., "Effects of $\mathrm{CO}_{2}$ on coal rapid pyrolysis behavior and chemical structure evolution," Journal of Analytical and Applied Pyrolysis, vol. 128, pp. 370-378, 2017.

[28] W. Zhang and C. Dai, "Pyrolysis characteristics of two mixed ligand of complexes soft coal and papermaking sludge," Coal Conversion, vol. 1, pp. 13-15, 2012.

[29] Y. Ma, S. Y. Li, J. Wang, and C. H. Fang, "Mechanism of oil shale pyrolysis under high pressure water," Journal of Fuel Chemistry and Technology, vol. 39, no. 12, pp. 881-886, 2011.

[30] M. Wang, L. Jin, H. Zhao et al., "In-situ catalytic upgrading of coal pyrolysis tar over activated carbon supported nickel in $\mathrm{CO}_{2}$ reforming of methane," Fuel, vol. 250, pp. 203-210, 2019.

[31] W. Qing, C. Da, C. Mingshu, Z. Hongxi, and X. Xiangcheng, "Influence of final retorting temperature on composition and property of Huadian shale oil," CIESC Journal, vol. 66, no. 7, pp. 2670-2677, 2015.

[32] X. Ru, Z. Cheng, L. Song, H. Wang, and J. Li, “Experimental and computational studies on the average molecular structure of Chinese Huadian oil shale kerogen," Journal of Molecular Structure, vol. 1030, pp. 10-18, 2012.

[33] Y. Lu, Y. Wang, J. Zhang, Q. Wang, Y. Zhao, and Y. Zhang, "Investigation on the characteristics of pyrolysates during copyrolysis of Zhundong coal and Changji oil shale and its kinetics," Energy, vol. 200, article 117529, 2020.

[34] Y. Zhao, M. Zhang, X. Cui, D. Dong, Q. Wang, and Y. Zhang, "Converting lignite to caking coal via hydro-modification in a subcritical water-CO system," Fuel, vol. 167, pp. 1-8, 2016.

[35] M. Wang, L. Jin, Y. Li, J. Lv, B. Wei, and H. Hu, "In-situ catalytic upgrading of coal pyrolysis tar coupled with $\mathrm{CO}_{2}$ reforming of methane over Ni-based catalysts," Fuel Processing Technology, vol. 177, pp. 119-128, 2018.

[36] E. Önal, B. B. Uzun, and A. E. Pütün, "Bio-oil production via co-pyrolysis of almond shell as biomass and high density polyethylene," Energy Conversion and Management, vol. 78, no. 13, pp. 704-710, 2014.

[37] Y. Sun, C. Yang, B. Liu, and Z. Hang, "Effect of water-oil ratio on residue hydrotreating in presence of supercritical water," Journal of China University of Petroleum, vol. 42, no. 2, pp. 160-164, 2018.

[38] Y. Zhao, Y. Wang, W. Wang, L. Tang, Q. Liu, and G. Cheng, "Modeling of rheological fracture behavior of rock cracks subjected to hydraulic pressure and far field stresses," Theoretical and Applied Fracture Mechanics, vol. 101, pp. 59-66, 2019.

[39] Y. Zhao, C. Zhang, Y. Wang, and H. Lin, "Shear-related roughness classification and strength model of natural rock joint based on fuzzy comprehensive evaluation," International Journal of Rock Mechanics and Mining Sciences, vol. 137, p. 104550, 2021.
[40] Y. Zhao, L. Zhang, W. Wang, Q. Liu, L. Tang, and G. Cheng, "Experimental study on shear behavior and a revised shear strength model for infilled rock joints," International Journal of Geomechanics, vol. 20, no. 9, article 04020141, 2020.

[41] Y. Zhao, Q. Liu, C. Zhang, J. Liao, H. Lin, and Y. Wang, "Coupled seepage-damage effect in fractured rock masses: model development and a case study," International Journal of Rock Mechanics and Mining Sciences, vol. 144, p. 104822, 2021. 